\title{
How future aircraft can benefit from a steerable main landing gear for crosswind operations
}

\section{Dennis Vechtel}

\begin{abstract}
Many unconventional configurations for future aircraft, such as aircraft with very high aspect ratio wings or blended wing bodies, suffer from adverse flying characteristics for crosswind operations. Although the reasons for such undesirable behavior are different, coming from either tight geometric limitations, such as small bank angle allowances close to ground, or unfavorable flying qualities in the lateral motion, the consequences are challenging characteristics for take-off or landing under crosswind. In the presented study a crosswind landing assistance system that makes use of a steerable main landing gear was designed and demonstrated in simulator trials. With such a system the so-called de-crab maneuver is obsolete and the aircraft can touch down in crabbed motion. During roll-out on ground the de-crab is performed automatically and the aircraft is kept on the runway centerline. A special concept for manual steering during this automatic de-crab on ground is introduced in the paper. The system is demon-
\end{abstract}

D. Vechtel

German Aerospace Center (DLR), Institute of Flight Systems, Lilienthalplatz 7, 38108 Braunschweig, Germany e-mail: dennis.vechtel@dlr.de strated in an A320 full-flight simulator with airline pilots, showing a good performance of the system and satisfactory pilot acceptance. The simulation results also show that the side forces acting on the landing gears could be reduced significantly with steerable main landing gears. This raises the hope that with such a system the landing gear could possibly be designed lighter, saving at least some of the additional weight and cost for the necessary steering actuators of the main landing gear.

Keywords crosswind landing - steerable landing gear . pilot assistance $\cdot$ simulator study
Abreviations
AFS
ATRA
Auto-Flight System
Advanced Technologies Research Air- craft
AVES
Air VEhicle Simulator
DLR
German Aerospace Center
EGT
Exhaust Gas Temperature
EPR
Engine Pressure Ratio
FCS
Flight Control System
FHS 


$\begin{array}{ll}\text { FMS } & \text { Flight Management System } \\ \text { GS } & \text { Ground Speed } \\ \text { HTP } & \text { Horizontal Tail Plane } \\ \text { IAS } & \text { Indicated Airspeed } \\ \text { ILS } & \text { Instrument Landing System } \\ \text { METAR } & \text { Meteorological Aerodrome Report } \\ \text { NASA } & \text { National Aeronautics and Space Admin- } \\ & \text { istration } \\ \text { SFB } & \text { Sonderforschungsbereich (collaborative } \\ & \text { research center) } \\ \text { STOL } & \text { Short Take-Off and Landing }\end{array}$

List of symbols

$F_{x}, F_{y}, F_{z}$ longitudinal, lateral and vertical component of the landing gear force $(\mathrm{N})$

$H \quad$ altitude (ft)

$k_{p} \quad$ gain for proportional controller (-)

$n_{y}, n_{z} \quad$ lateral and vertical load factor (-)

ptire $\quad$ tire pressure $\left(\mathrm{N} / \mathrm{m}^{2}\right)$

$T_{\text {Track }} \quad$ time constant (s)

$u, v \quad$ longitudinal and lateral velocity component of tires $(\mathrm{m} / \mathrm{s}) /(\mathrm{kts})$

$V \quad$ air speed $(\mathrm{m} / \mathrm{s}) /(\mathrm{kts})$

$V_{\text {Ground }} \quad$ ground speed $(\mathrm{m} / \mathrm{s}) /(\mathrm{kts})$

$X T E_{R W Y} \quad$ cross track error on the runway (m)

$\delta_{\text {brake }} \quad$ proportion of braking applied (-)

$\eta_{N G} \quad$ nose gear steering angle $\left(^{\circ}\right)$

$\eta_{M G} \quad$ main gear steering angle $\left(^{\circ}\right)$

$\mu_{s} \quad$ side-friction coefficient (-)

$\mu_{b} \quad$ brake-friction coefficient (-)

$\mu_{r} \quad$ roll-friction coefficient (-)

$\Psi \quad$ aircraft heading $\left({ }^{\circ}\right)$

$\Psi_{R W Y} \quad$ runway heading $\left({ }^{\circ}\right)$

$\Delta \Psi_{\text {crab }} \quad$ crab angle $\left(^{\circ}\right)$

$\tau \quad$ skid angle $\left({ }^{\circ}\right)$

$\chi \quad$ track angle $\left({ }^{\circ}\right)$

$\Delta \chi_{\text {chase }} \quad$ chase angle $\left(^{\circ}\right)$

$\chi_{C M D} \quad$ commanded track angle $\left(^{\circ}\right)$

\section{Introduction}

Today's aircraft configurations have been optimized since decades. Since the dawn of the jet age in the 1950s the wing-and-tube configuration can be considered as the classical configuration for transport aircraft [1]. In those days, due to low fuel prices, fuel burn was not as important as today and environmental issues, such as emission of greenhouse gases, were almost irrelevant. Since then, due to increasing fuel cost and growing importance of environmental issues, aircraft were subject to a vast optimization. This, in the end, had the aim to lower the operational cost for the aircraft operator [2]. This optimization was mainly achieved by lowering the structural weight, by increasing the aerodynamic efficiency of the aircraft, and by increasing the efficiency of the engines.

After more than half a century of evolutionary optimization the classical aircraft configuration has become so efficient that a further increase in efficiency requires enormous technical effort. However, for many feasible technical solutions the increasing complexity clashes amongst others with the aircraft manufacturer's needs for large production rates in order to cope with growing air traffic. Also, it is foreseeable that worldwide the issue of the environmental impact of air traffic will gain importance even more than today [3]. With the current classical aircraft configuration it might possibly be challenging to meet all these future requirements for aircraft design.

For these reasons many different unconventional aircraft configurations are currently under investigation. It is not yet clear, which aircraft configuration will be the future for aviation, whether it will be electrically powered or classical fuel-powered aircraft, classical wing-and-tube configurations with very high aspect ratio wings or more unconventional configurations, such as the blended wing body, or even totally different aircraft configurations. Certainly, this will also depend on the desired purpose and the envisaged mission of the specific aircraft. However, it is likely that more radical changes to the aircraft design than in the past will be necessary in order to meet with future requirements and demands.

Figure 1 depicts some examples of unconventional aircraft, which are currently under investigation or have been investigated in the past as possible candidates for future transport aircraft. The Figure $1 \mathrm{a}$ ) and b) show two different aircraft configurations with strut-braced-wings with very high aspect ratio, investigated by Boeing and NASA in the SUGAR (subsonic ultra-green aircraft research) study [4]. Figure 1 c) and d) show different designs for blended wing bodies investigated by DLR [5] (Fig. 1 c)) and Boeing [6] (Fig. 1 d)). Figure 1 e) shows a design by the German nationally-funded Sonderforschungsbereich 880 [7] (collaborative research center, SFB 880), a project conducted by the universities of Braunschweig and Hannover and DLR. At first glance the SFB 880 design looks almost conventional, but the aim of the project is to investigate future active high-lift systems for improved STOL (short take-off and landing) capabilities. 


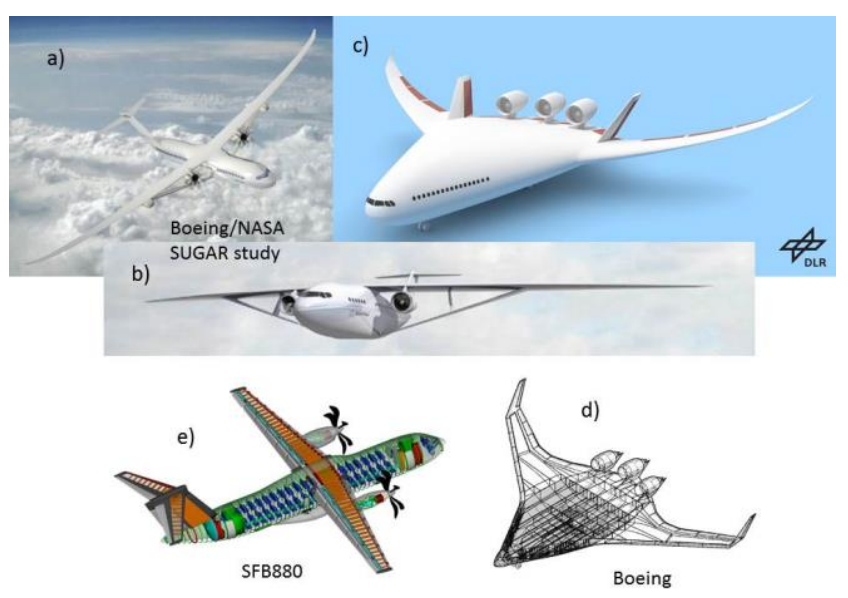

Fig. 1 Examples of unconventional future aircraft configurations [4-7]

As different as all the unconventional aircraft configurations shown in Figure 1 are, they all suffer from the same operational concern, namely a poor ability to properly handle crosswind during landing. The reason for this challenging behavior is as different as the aircraft configuration themselves. On the one hand it comes from geometric limitations in terms of maximum allowable bank angle for wing tip clearance for those aircraft with very high aspect ratio wings. On the other hand it comes from poor controllability and handling qualities as known for aircraft such as blended wing bodies [5] (which might also suffer from geometric limitations during landing). Also, aircraft with active high-lift systems showed challenging lateral stability and controllability, which limits operations under crosswind. Such a behavior was shown during flight tests of the NASA already in the 1960s [8][9] and was recently confirmed by investigation performed within the SFB 880 [10].

Crosswind during take-off and landing is critical for those aircraft which are sensitive to sideslip angles. During crosswind operations excessive sideslip angles occur especially on ground, when the aircraft has to follow the runway, thus cannot act as a weathercock. On ground the resulting yawing moments due to the sideslip angle can typically be compensated by the rudder and/or the nose gear steering. During take-off, when the aircraft is airborne, the weathercock stability of the aircraft automatically heads the aircraft into the wind. For this reason take-off under crosswind is less complex compared to crosswind landings. Landing under strong crosswind indeed requires more control effort from the pilot. Transport aircraft are usually approaching the runway with wings level and a socalled crab angle in windward direction to compensate for the wind drift [11] (s. Fig. 2). This means that during the approach the aircraft's longitudinal axis does not point in runway direction. In order to touch down the aircraft aligned with the runway the so-called de-crab maneuver needs to be performed shortly prior touch-down during the flare. This highly dynamic maneuver can be challenging for pilots especially under strong winds and gusty conditions.

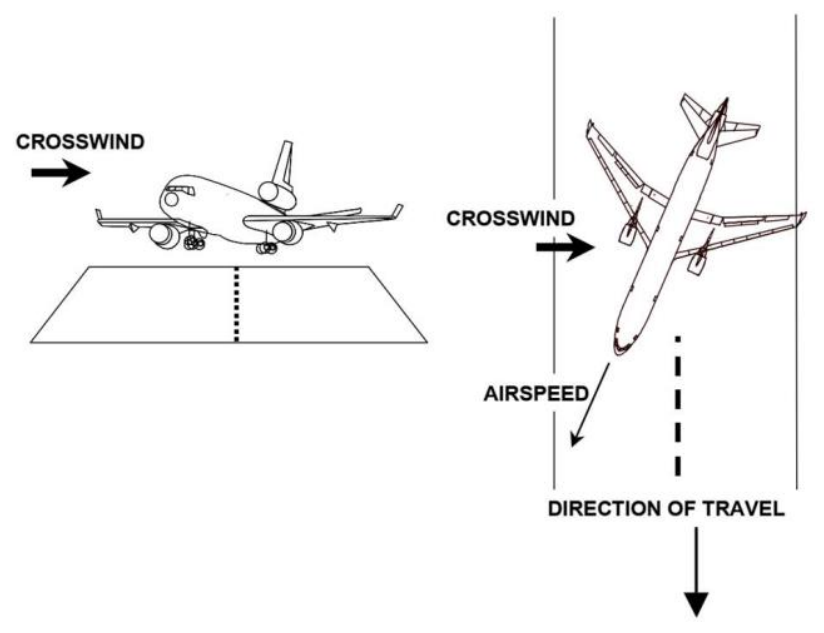

Fig. 2 Preferred landing technique under crosswind for transport aircraft: the crabbed approach [28]

With present aircraft the controllability and geometrical limitations (such as bank angle allowances close to ground) are well sufficient to perform this maneuver and the maximum demonstrated crosswinds are typically in the order of magnitude of around 30-40 kts (e.g. $33 \mathrm{kts} /$ gust $38 \mathrm{kts}$ for A320 [12]). This value is indeed not limiting for operations and it is the pilot's decision to perform a landing even under stronger crosswind conditions. Runway contamination (such as wet runway surface or standing water on the runway) is another factor, which increases the risk during landings under crosswinds. For this reason the maximum crosswind recommended by the Flight Safety Foundation is reduced from 35 kts with good reported braking action to $25 \mathrm{kts}$ with medium and $15 \mathrm{kts}$ with poor reported braking action [11]. Even though today crosswind-related accidents occur only rarely, crosswind contributes to a significant amount to weather-related accidents, especially in combination with wet runways [11].

For future aircraft, which may suffer from poor lateral controllability or tight geometric limitations close to ground, crosswind during take-off and especially during landing may pose a much bigger challenge. In order to avoid an increased accident risk and to at least maintain the present safety level technical and operational means can be found. Aviation history showed that in the past those air- 
craft, which suffered from challenging handling qualities or tight geometric limitations for crosswind operations, were designed with special landing gears that enabled the aircraft to touch-down in crabbed motion. The avoidance of the de-crab maneuver, hence the avoidance of large sideslip angles at higher speeds, reduces the risk of crosswind-related accidents significantly. This requires of course that all wheels of the aircraft can be aligned in runway direction. For this different technical solutions are feasible. Modern electronic flight control systems may also give the opportunity to assist the pilot during crosswind operations.

A crosswind landing assistance system, which makes use of steerable main landing gears, was investigated by DLR Institute of Flight Systems in a DLR internally funded project [13] and an EU-funded project "Future Sky Safety -Solutions for runway excursions" (Grant Agreement No. 640597). This paper will give insight in the design of the assistance system, the simulation modelling for the analyses and simulator trials with pilots in a full-flight simulator. First, a historical overview on existing technical solutions for improving crosswind landing capabilities is given, followed by the description of the work performed by DLR during the last years. Finally, conclusions on how future aircraft can benefit from steerable main landing gears and a crosswind assistance system will be given.

\section{Existing Solutions}

In the early days of aviation aircraft were usually designed as taildragger aircraft, meaning that the main wheels are in front of the center of gravity of the aircraft with a single wheel at the aft of the aircraft. Under crosswind such aircraft are challenging to land due to their tendency to uncontrollably steer into the wind performing a ground loop (s. Fig. 3 left). A simple technical solution to prevent such ground loops was to use castering wheels for the main landing gears, so that the wheels automatically turn in landing direction after touch-down [14]. This way the aircraft can be touched down in crabbed motion (s. Fig. 3 right). One example for taildragger aircraft with castering main wheels are the Cessna 190 and 195 [15]. However, during turns while taxiing castering wheels decrease ground handling.

The problem of crosswind-related ground loops was, however, eliminated with the introduction of main landing gears located behind the center of gravity and a steerable nose wheel, the typical undercarriage used for transport aircraft until today. With such a landing gear the aircraft tends to automatically align itself in landing direction if a residual crab angle still exists during touch-down. In this case a touch-down in slightly crabbed motion indeed results in excessive side forces on the tires and landing gear struts (possibly leading to severe tire damages), but it does not lead to uncontrollable aircraft behavior such as with taildragger aircraft. Since then crosswind plays a lesser role for operations of transport aircraft given a geometrical layout that allows for sufficient attitude clearance.
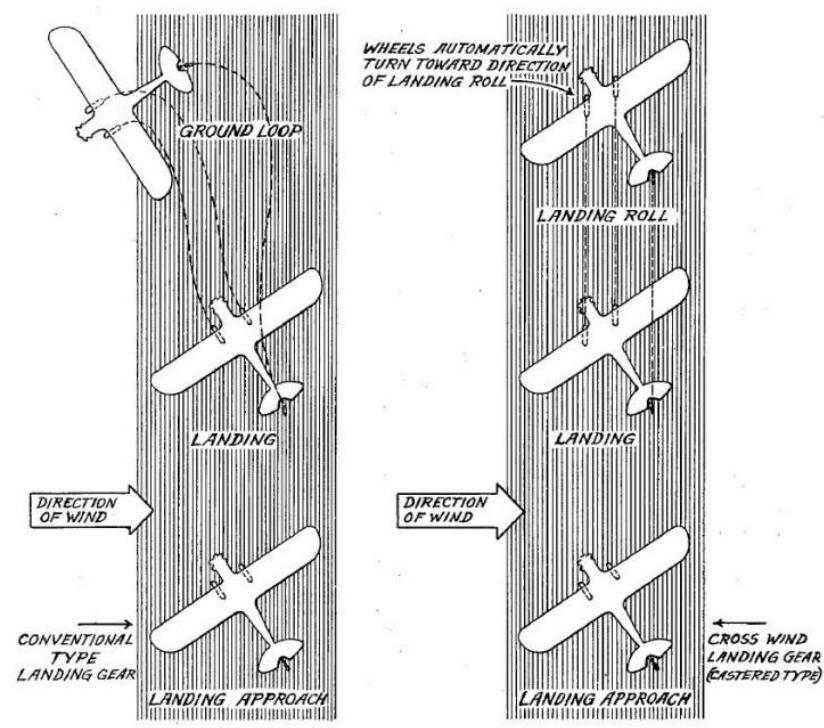

Fig 3. Prevention of ground loop of taildragger aircraft under crosswind by using castering wheels [14]

An aircraft that suffers from tight geometric limitations is the B-52. This aircraft has very little wing tip clearances, for which reason it would be very challenging to perform crosswind landings. Even if controllability is sufficient to build-up larger sideslip angles, the risk to contact ground with the wingtips during a de-crab maneuver under gusty crosswind conditions would be high for this aircraft. For this reason the B-52 was designed with a tandem landing gear that allows steering of all gears. This way the B-52 is able to perform crabbed landings (s. Fig. 4).

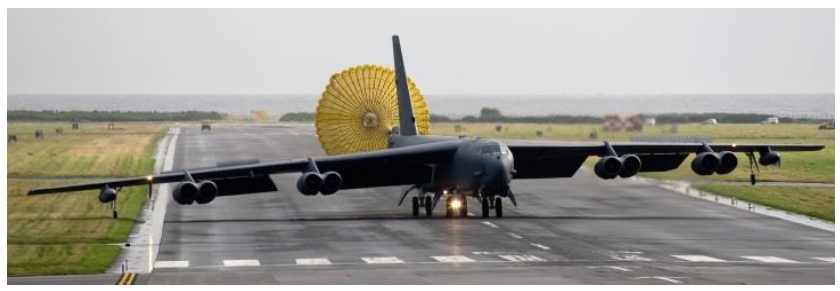

Fig. 4 Crabbed landing of a Boeing B-52 under crosswind [Photo: Michael Hall] 
The crosswind crab system of the B-52 allows the steering of all wheels in the direction of the ground track (in Fig. 5 called "desired heading") [16]. The crab angle steering is set by the pilot through a crosswind crab control knob (s. Fig. 5) to a fixed value, which is the expected crab angle at touch-down. This way the aircraft can touch-down in crabbed motion, keeping the relative angle between runway and aircraft constantly afterwards. During roll-out the aircraft is steered conventionally by rudder and the front wheels. After roll-out the landing gear is centered so that the aircraft can taxi conventionally.

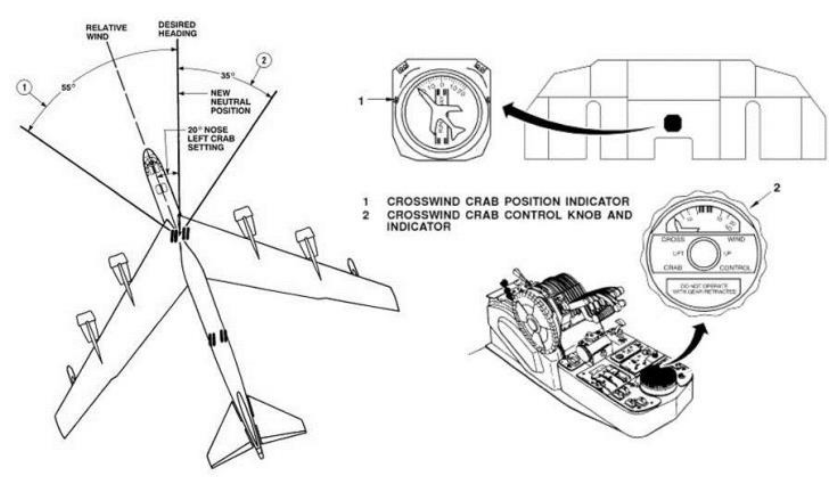

Fig 5. Boeing B-52 Landing Gear Steering and Crosswind Crab Systems [16]

Both technical solutions, the castering wheels and the B-52 crosswind crab system, allow the pilot to land the aircraft in crabbed motion and show a compromise between aircraft configuration design and crosswind landing capabilities. These examples show that in the past aircraft configurations that showed challenging flying characteristics for crosswind operations resulted in the development of special landing gear designs in order to allow safe operations under the presence of crosswind. In case that future aircraft configurations show such adverse characteristics as well, it is only logical to use the landing gear design again as a means to improve crosswind capabilities of that aircraft instead of e.g. installing enormously large control surfaces to allow performing a de-crab maneuver or change the overall aircraft design. With modern electronic flight control systems it is also feasible not just to allow the pilot to land in crabbed motion but also to assist the pilot during crosswind landings after touchdown on the runway. Ideas for the application of such automatic crosswind assistance systems were claimed e.g. in patents by Boeing [17] and DLR [18].

\section{Development of the Crosswind Assistance Sys- tem}

The aim of the crosswind assistance system developed by DLR is to

- enable crabbed landings by using steerable main landing gears, and

- to assist the pilot during crosswind operations by performing the de-crab on ground automatically and to keep the aircraft on the runway centerline.

The assistance system shall be operable in manual flight as well as with autoland engaged. This way the scope of autoland operations could be enlarged in the future. Today, autoland is only certified for low visibility operations. Also, the maximum allowed crosswind for autoland landings is much lower than for manual flight (e.g $20 \mathrm{kts}$ for A320 [19]). Future aircraft equipped with a crosswind assistance system could also use the autoland system for crosswind landings regardless of the visibility (keeping in mind that in such case the CATIII obstacle clearances need to be obtained as well to allow proper functionality of the ILS). The assistance system was developed such that it works both in manual flight or with autopilot/autoland engaged.

As landing is the more crucial case for operations under strong crosswind the assistance system was only developed and tested for landings. To develop a take-off mode is preferable but not scope of the work presented here (s. section 5). As development and testing platform the A320 was chosen here. Of course, this aircraft type has no special needs for such a crosswind assistance system and it is not intended to investigate possibilities for a retrofit solution for the A320. However, the DLR Institute of Flight Systems has developed an accurate simulation model of the A320 based amongst others on flight test data gathered from the real DLR research aircraft A320 ATRA (Advanced Testing Research Aircraft) and also operates a fullflight simulator with this simulation model. It is assumed that the demonstration of the functionality of this system could be performed independently from the specific aircraft type, so that it is not necessary to use a model of future unconventional aircraft, such as outlined in section 1 , for this kind of investigation.

\subsection{The Assistance System}

The crosswind assistance system has to perform various tasks during approach, landing and roll-out. Some of these tasks need to be performed in parallel, some sequentially. Actually, the following tasks can be listed: 
- Alignment of all landing gears prior touchdown, enabling touch down in crabbed motion,

- Performing the de-crab on the runway during roll-out, enabling taxying with the main gears aligned in the aircraft's longitudinal direction,

- Steering the aircraft on the runway towards the centreline,

- Allowing manual steering commands by the pilot.

The different phases and tasks to be performed by the assistance system during a crosswind landing are depicted in Fig. 6. Based on the general controller architecture described above the controllers were developed as described in the following.

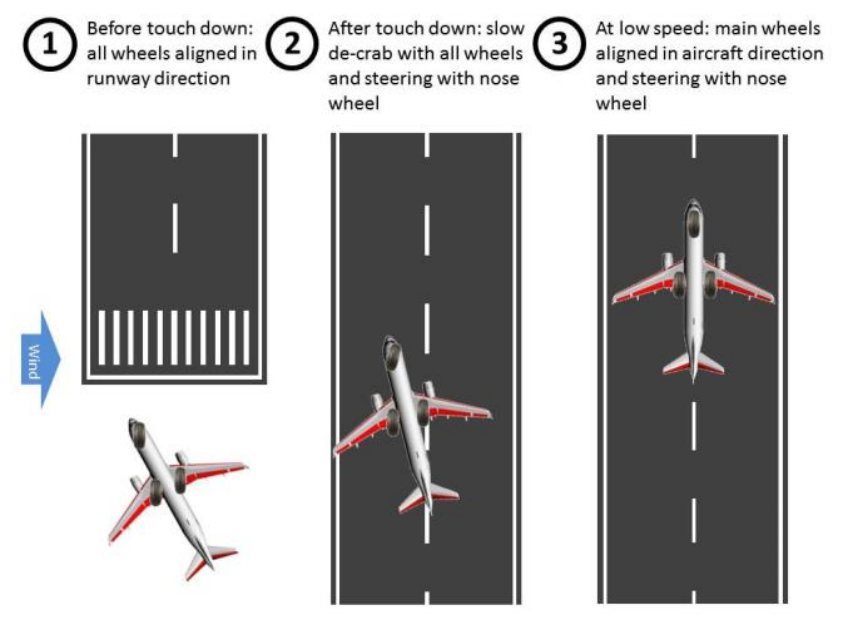

Fig. 6 Working principle of the crosswind landing assistance system

During approach, prior touchdown, each landing gear must be aligned in the same direction, enabling a crabbed touchdown. Previous studies in the context of the DLR project mentioned in section 1 showed that if all tires are aligned in the direction of the current ground track, the lateral displacement from the centerline is larger in case of lateral drift before touchdown than if all tires are aligned with the runway. Alignment in runway direction might indeed result in small lateral loads on the gear struts if the aircraft drifts slightly sideways above the runway; however ground control is improved this way. For this reason, the crosswind assistance system as developed in the present study aligns all landing gears in runway direction prior touchdown. At touchdown (i.e. when all main landing gears detect weight on wheels) the current steering angle to compensate the crab angle is frozen and afterwards slowly reduced to zero during roll-out. Actually, the crab angle
$\Delta \Psi_{c r a b}$ is reduced on a quadratic, speed-dependent scale so that the crab angle is zero at a ground speed of $30 \mathrm{kts}$.

Before touchdown:

$\Delta \Psi_{c r a b}=\Psi_{R W Y}-\Psi$

After touchdown and $V_{\text {ground }}>30 \mathrm{kts}$ :

$\Delta \Psi_{c r a b}=\left[\frac{V_{\text {ground }}[k t s]-30}{V_{\text {ground }, T / D}[k t s]-30}\right]^{2} \cdot \Delta \Psi_{c r a b, T / D}$

After touchdown and $\mathrm{V}_{\text {ground }} \leq 30 \mathrm{kts}$ :

$\Delta \Psi_{c r a b}=0$

with the aircraft heading $\Psi$, the runway heading $\Psi_{R W Y}$, the current ground speed $V_{\text {ground }}$ (in kts), the ground speed at touchdown $V_{\text {ground,T/D }}$ (in kts), and the crab angle at touchdown $\Delta \Psi_{c r a b, T / D}$. The quadratic term leads to a quicker de-crab at higher speeds than e.g. a linear reduction of the crab angle. This way, the aircraft is being quickly and safely de-crabbed on ground during roll-out. Below a ground speed of $30 \mathrm{kts}$ the crab angle is always zero, assuring a conventional taxying with the main gears aligned in the aircraft's longitudinal direction.

The ground track controller is similar to the conventional autoland's directional controller that tries to keep the aircraft on the runway's centerline. The input for this controller is the localizer signal and the error from it is kept to zero. The control device for the ground track controller is only the nose gear. The rudder is not used as control surface by the assistance system. However, it would be useful to investigate the benefit from using the rudder for ground control as well (at least at higher speeds).

In case of a displacement from the runway centerline / localizer, which here is called cross track error on the runway $X T E_{R W Y}$, a chase angle is calculated using the current ground speed $V_{\text {ground }}$ and a predefined time constant $T_{\text {track }}$. The cross track error $X T E_{R W Y}$ is the lateral displacement from the runway centerline (in meters) and is calculated with the localizer signal (representing an angular displacement from the localizer) and the distance to the localizer antenna.

The nose gear steering angle command $\eta_{N G}$ is a function of the commanded track $\chi_{c m d}$.

$$
\eta_{N G}=k_{p, \eta_{N G}} \cdot \chi_{c m d}
$$

The track command $\chi_{C M D}$ is calculated by means of the current heading $\Psi$, the (speed-dependent) crab angle $\Delta \Psi_{c r a b}$, the runway heading $\Psi_{R W Y}$ and the runway-related chase angle $\Delta \chi_{\text {chase }}$ to lead the aircraft to the runway cen- 
terline. For larger deviations from the runway centerline or larger differences between the current track and the runway azimuth, the track command is a simple proportional controller.

$$
\chi_{c m d}=k_{p, \chi} \cdot\left(\Psi_{R W Y}-\Psi-\Delta \Psi_{c r a b}\right)+\Delta \chi_{\text {chase }}
$$

For small deviations an additional integration part is activated in order to eliminate the remaining control error. Actually, if $\left|X T E_{R W Y}\right|<10 \mathrm{~m}$ and $\left|\Psi_{R W Y^{-}} \Psi-\Delta \Psi_{c r a b}\right|<3^{\circ}$ the track command $\chi_{C M D}$ is calculated by the following equation:

$$
\begin{aligned}
\chi_{c m d}= & k_{p, \chi} \cdot\left(\Psi_{R W Y}-\Psi-\Delta \Psi_{\text {crab }}\right)+\left(\Delta \chi_{\text {chase }}+\right. \\
& \left.k_{i} \int X T E_{R W Y} d t\right)
\end{aligned}
$$

The chase angle is calculated as a function of the cross track error on the runway $X T E_{R W Y}$, the ground speed $V_{\text {ground }}$ and a time constant $T_{\text {track }}$ (s. Fig. 7).

$$
\Delta \chi_{\text {chase }}=\arctan \left(\frac{X T E_{R W Y}}{T_{\text {track }} \cdot V_{\text {ground }}[\mathrm{m} / \mathrm{s}]}\right)
$$

This way, the controller steers the aircraft more smoothly towards the runway centerline at higher speeds.

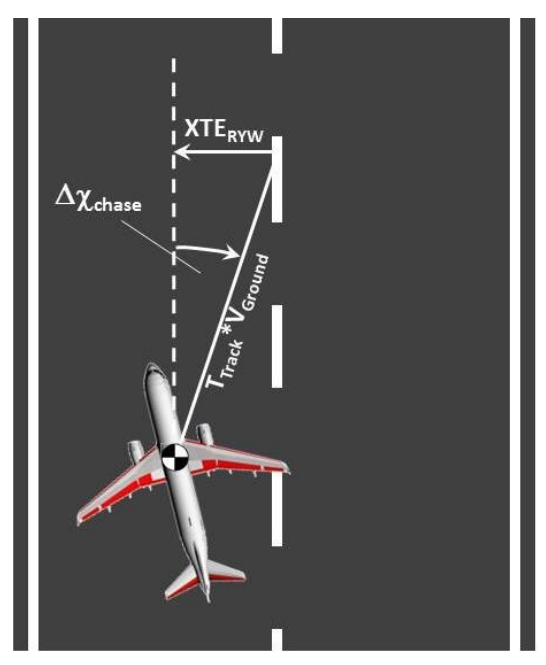

Fig. 7 Chase angle to lead the aircraft towards the runway centerline

The ground track controller acts similar to current autoland systems, using the localizer signal for keeping the aircraft on the runway centerline by steering the nose wheel. Although it is generally also possible to use the rudder in addition to the nose wheel for steering the aircraft on ground, the crosswind landing assistance system does not make use of the rudder and uses solely the nose wheel. This is for reasons of simplicity and to demonstrate the potential of the assistance system by only using the landing gear for steering.

The dynamics of the nose wheel steering are limited to an angular rate of $12 \%$. The dynamics of the main landing gear steering are not limited for the present study. However, during the simulations the steering rate of the main landing gear did not exceed $2.5 \%$. This implies that the required steering rate for the main gear steering actuators is possibly lower than the for the nose wheel steering.

Besides the nose wheel steering command, calculated by the automatic ground track controller described above, the pilot can also manually steer the aircraft via the nose wheel on ground. However, as the ground track controller always tries to steer the aircraft towards the runway centerline, manual steering on ground with the assistance system engaged needs to be adapted in comparison to conventional ground control. During preliminary tests in a flight simulator different concepts for manual steering were tested. The simplest concept e.g. was a pure manual nose wheel steering, where the pilot always has to perform the de-crab on the runway with the nose wheel. This concept often ended up in runway veer-offs as the reduction of the crab angle on the main wheels lets the aircraft head away from the runway centerline, which needs to be compensated by the pilot by nose wheel steering. Other concepts e.g. by commanding a yaw rate with the pedals also not showed satisfying characteristics for an intuitive manual steering. The concept described in the following showed the most promising results and was fully accepted by all pilots after some familiarization time in the simulator study described in section 4. Generally, the pilot's intention is to steer the aircraft to the left or right by manual steering inputs but as long as he does not intend to exit the runway on a taxiway the general direction is the runway direction with slight corrections to either side. As the crab controller always needs a reference for aligning the aircraft during de-crab on ground the localizer signal is used. For manual steering the localizer signal (hence, the runway centerline) is artificially moved to the side to which the pilot wants to steer (s. Fig. 8). By doing so, the crosswind assistance system steers the aircraft towards this artificial centerline while it continues to de-crab the aircraft with reference to the changed centerline. For manual control input the pedals are used so that the pilot is able to manually steer the aircraft while the assistance system is still active, performing the de-crab and keeping the aircraft on the runway. Below a ground speed of $30 \mathrm{kts}$ the assistance system is disabled and manual steering of the aircraft is performed conventionally by directly steering the nose wheel via pedals and tiller. 

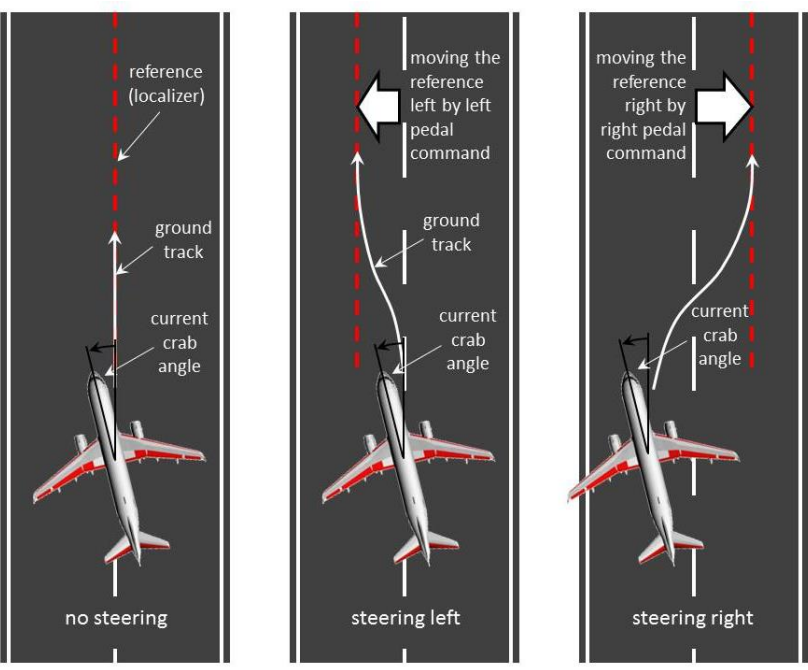

Fig. 8 Working principle of the crosswind landing assistance system

\subsection{Aircraft Simulation}

The aircraft simulation model consists of various parts comprising different sub-models:

- Aircraft model

- Control surface and landing gear actuators

- Weight and balance calculation

- Rigid-body aerodynamics

- Propulsion

- Landing Gear

- Sensors (radio altimeters, air data system, inertial reference, navigation beacon sensors)

- Equations of motion

- Environment model

- Wind and turbulence

- Standard atmosphere

- Gravitation

- Terrain elevation

- Aircraft controller

○ Autopilot

- Auto-thrust

- Control laws for manual flight (normal, alternate and direct law)

- Crosswind Assistance System

The simulation model was developed amongst others by means of flight test data gathered with the A320 ATRA. The model accuracy is considered to be fully adequate for scientific purpose [20].
For the application of steerable main landing gears all three landing gears of the A320 are modelled in the same way, except that the nose wheel does not comprise brakes. The modelling of the landing gear as a rigid-body follows the approach of Fischenberg [21], based on Barnes and Jager [22].

The vertical force $F_{z}$ is modelled as the sum of a spring force and a damper force $[21,22]$.

$$
F_{z}=F_{\text {spring }}+F_{\text {damper }}
$$

The spring force $F_{\text {spring }}$ is a non-linear function of the oleo deflection as shown in Figure 9.

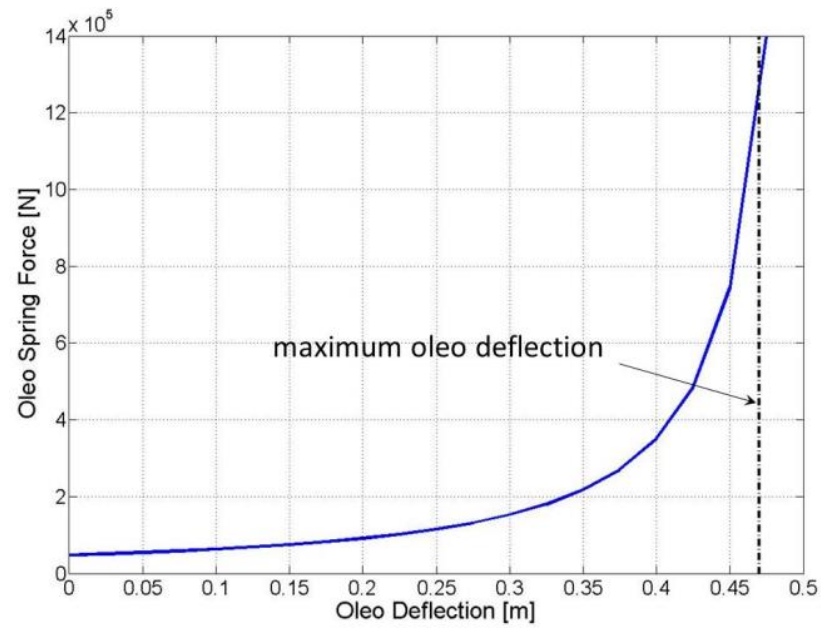

Fig. 9 Oleo spring force as a function of the oleo deflection

The oleo damping force is a quadratic function of the oleo compression rate $\dot{f}_{O}$ for each direction. The constants for compression and decompression $K_{1}$ and $K_{2}$ differ by a factor of 2 [21,22].

$$
F_{\text {damper }}= \begin{cases}K_{1} \cdot \dot{f}_{o}{ }^{2} & : \text { Compression } \\ -K_{2} \cdot \dot{f}_{O}{ }^{2} & : \text { Decompression }\end{cases}
$$

The functions for spring and damper forces are different for the main gears and the nose gear. The forces are adapted to the geometry and weight of the A320.

The longitudinal force of the main landing gears is a function of the vertical force $F_{z}$ and the brake-friction coefficient $\mu_{b}[21,22]$.

$$
F_{x}=F_{z} \cdot \mu_{b}
$$

The brake-friction coefficient is modelled as a function of the maximum brake-friction coefficient $\mu_{b, \max }$, the pro- 
portion of braking applied $\delta_{\text {brake }}$ (between 0 for "brake release" and 1 for "full brake"), the roll-friction coefficient $\mu_{r}$ and the longitudinal velocity of the wheel $u$ (in kts, s. Fig. 9) $[21,22]$.

$$
\begin{aligned}
\mu_{b}= & \left(-0.03+0.94 \cdot \mu_{b, \max }\right) \cdot \delta_{\text {brake }}+\mu_{r}+0.002 \\
& (10-|u|)
\end{aligned}
$$

Figure 10 depicts the geometric relations at the wheel.

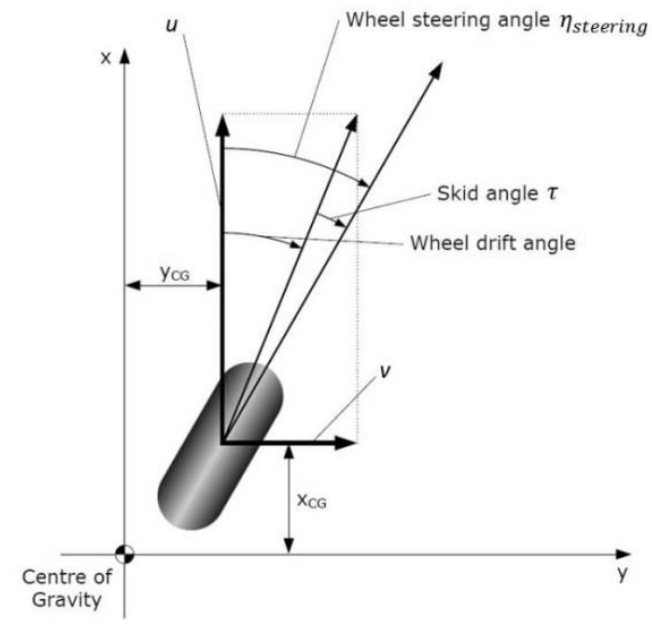

Fig. 10 Geometric relations at the steerable wheel

The roll friction coefficient $\mu_{r}$ is set to a value of 0.03 for each gear $[21,22]$. The maximum brake-friction coefficient $\mu_{b, \max }$ is modelled as a function of the tire pressure $p_{\text {tire }}$ and/or the longitudinal velocity of the wheel $u$ (in kts) for different runway conditions $[21,22]$.

dry runway:

$\mu_{b, \max }=0.912 \cdot\left(1-0.0011 \cdot p_{\text {tire }}\right)-0.00079 \cdot u$

wet runway:

for u < $140 \mathrm{kts}$ :

$\mu_{b, \max }=(1-0.0052 \cdot u) \cdot\left(0.91-0.001 \cdot p_{\text {tire }}\right)$

for $\mathrm{u}>140 \mathrm{kts}$ :

$\mu_{b, \max }=0.265 \cdot\left(0.91-0.001 \cdot p_{\text {tire }}\right)$

For the nose gear the longitudinal force is calculated only with the roll friction coefficient $\mu_{r}[21,22]$.

$$
F_{x, N G}=F_{z, N G} \cdot \mu_{r}
$$

The side force $F_{y}$ is a function of the vertical force $F_{z}$, and the side-friction coefficient $\mu_{s}$. The sign of the side force equals the sign of the skid angle of the wheel $\tau$ [21,22].

$$
F_{y}=-F_{z} \cdot \mu_{s} \cdot \operatorname{sign}(\tau)
$$

The skid angle $\tau$ is a function of the steering angle $\eta_{\text {steering }}$ and the longitudinal and lateral velocities of the wheel $u$ and $v[21,22]$.

$$
\tau=\eta_{\text {steering }}-\arctan \left(\frac{v}{u}\right)
$$

The velocity components at the wheel $\mathrm{u}$ and $\mathrm{v}$ are calculated with the geodetic velocity component of the aircraft at the center of gravity $u_{k}$ and $v_{k}$ (in $\mathrm{m} / \mathrm{s}$ ) and the rotational components from the roll, pitch and yaw rates $p, q$ and $r$ with the respective lever arms of the wheel $x_{C G}, y_{C G}$ and $z_{C G}$.

$$
\begin{aligned}
& u=u_{k}+q \cdot z_{C G}-r \cdot y_{C G} \\
& v=v_{k}+r \cdot x_{C G}-p \cdot z_{C G}
\end{aligned}
$$

The side-friction coefficient $\mu_{s}$ is calculated with the skid angle $\tau$ and the maximum side-friction coefficient $\mu_{s, \max }[21,22]$.

$$
\mu_{s}=\mu_{s, \max } \cdot\left|\frac{4 \cdot \tan (\tau)}{\mu_{s, \max }}-0.148 \cdot\left(\frac{4 \cdot \tan (\tau)}{\mu_{s, \max }}\right)^{3}\right|
$$

The maximum side-friction coefficient $\mu_{s, \max }$ varies with the runway condition. For the dry runway the maximum side-friction coefficient is modelled to be equal the maximum brake-friction coefficient $\mu_{b, \max }$ and for wet runway $\mu_{s, \max }$ is a function of $\mu_{b, \max }[21,22]$.

dry runway: $\mu_{s, \max }=\mu_{b, \max }$

wet runway: $\mu_{s, \max }=0.64 \cdot \mu_{b, \max }+0.15 \cdot \mu_{b, \max }^{2}$

Other important sub-models of the flight simulation model are described only briefly and not at the same level of detail as the landing gear model. The aerodynamic model of the aircraft simulation is a derivative model with stability and control derivatives. In longitudinal motion the aerodynamics are modelled as a two-point model, comprising wing and horizontal tail (HTP), whereas for lateral motion the aerodynamics is just a one-point model. A detailed description of the aerodynamics model and the validation is given by Raab [20].

The propulsion model is a quite simple lookup-table model. In order to represent the engines dynamics the 
power lever signal is delayed by using PT2-dynamics. Engine pressure ratio EPR, fuel flow, exhaust gas temperature EGT, the revolutions of the low-pressure and highpressure shafts $\mathrm{N} 1$ and $\mathrm{N} 2$ and thrust are a function of the following inputs: power lever, altitude, temperature offset from standard atmosphere and Mach number. The lookuptables are adapted to the characteristics of the A320's V2500 engine and validated by means of flight test data and the Airbus A320 performance calculation software PEP [29].

The aircraft simulation comprises a comprehensive flight control (FCS) and auto-flight (AFS) system model. This model was adapted to the architecture of the A320 FCS/AFS. For manual flight the Airbus-typical "normal law", allowing rate-command/attitude-hold control, can be used, as well as a direct law, allowing direct control of the control surfaces (not used in the present study). An autopilot and auto-thrust system exists as well, comprising all modes of the Airbus AFS, including autoland. The dynamics of this auto-flight system was adapted to that of the A320 based on flight data from the real aircraft.

\section{Flight Simulation Test}

For first tests of the crosswind assistance system's capabilities offline simulations were performed with autoland engaged. These simulations were performed with different crosswind components up to $50 \mathrm{kts}$. The runway conditions considered during these simulations were dry and wet runway. Generally, the assistance system showed a very good performance, keeping the deviations from the centerline below a few meters. With wet runway conditions the accuracy was slightly degraded, but even with $50 \mathrm{kts}$ crosswind and wet runway the assistance system was able to keep the aircraft on the runway. However, as the influence of the runway conditions on the accuracy of the assistance system needs further investigation the simulation results with wet runway should not be further discussed here. The following discussions solely refer to dry runway conditions.

Figure 11 outlines exemplary results from the offline simulations with autoland engaged with a crosswind component of $40 \mathrm{kts}$ and dry runway conditions. The figure shows the simulation run from shortly prior touchdown until stand-still represented by the aircraft's altitude $\mathrm{H}$ and speed V (in terms of indicated air speed IAS and ground speed GS), heading $\Psi$ and ground track $\chi$, the steering angles $\eta_{\text {steering }}$ of the nose and main gears, the lateral and vertical load factors $\Delta n_{z}$ and ny and the lateral deviation from the centerline on the runway $X T E_{R W Y}$.
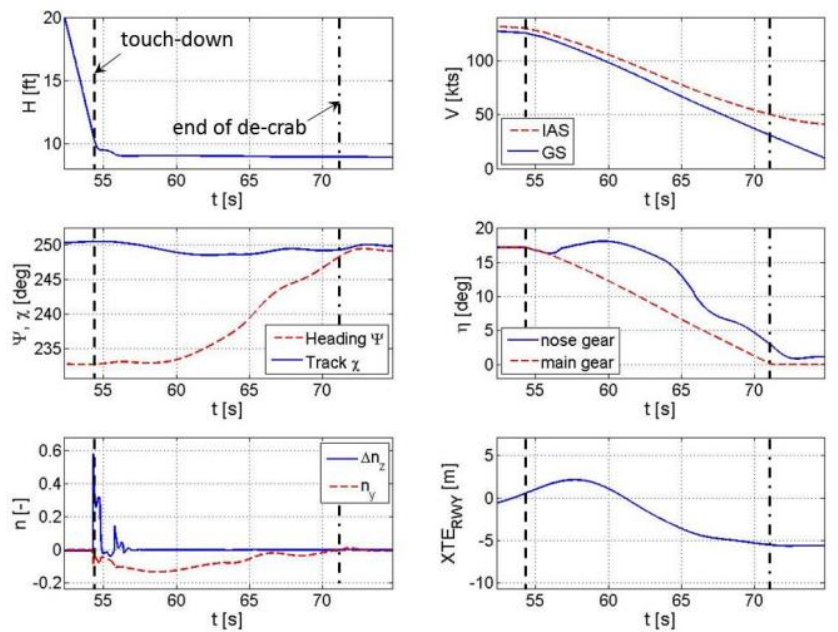

Fig. 11 Simulation results for $40 \mathrm{kts}$ crosswind and autoland with the crosswind assistance system

One can clearly observe in Figure 11 the crab angle as the large difference between heading and ground track (here about $17^{\circ}$ shortly prior touchdown). The plot of the landing gear steering angles shows exactly this value before touchdown, showing that all landing gears are aligned in runway direction in flight. The plot of the vertical load factor shows the touchdown at about $54 \mathrm{~s}$ of simulation time. After touchdown the main gear steering angle is slowly reduced to zero corresponding to the ground speed (s. Eq. (2), but here, for test reasons on a linear scale). The steering angle of the nose gear shows that the aircraft is steered on the runway in order to keep the aircraft in the centerline. One has to keep in mind that typically the maximum steering angle of the nose wheel is limited to only a few degrees at high speeds. In order to allow crabbed landings this limitation needs to be adapted, allowing for larger deflections. The figure shows that even under these strong crosswind conditions the assistance system is able to keep the aircraft on the centerline within a range of only few meters.

After the successful offline-tests the assistance system was implemented in the A320 full-flight simulator AVES (Air Vehicle Simulator) [24]. AVES comprises a motionbased and a fixed-base simulator with interchangeable cockpits of the two DLR research aircraft A320 ATRA (Advanced Technology Research Aircraft) and EC135 FHS (Flying Helicopter Simulator). The complete software for the simulators (such as e.g simulator control, aircraft model, FMS, systems simulations, visual system or cockpit displays) was developed and programmed in-house by DLR, which allows full access and possibility for adaptation for scientific purposes. Figure 12 shows the outside view of the AVES motion-simulator and the inside view of 
the A320 cockpit. In order to allow full flexibility for scientific purposes the simulator is not certified for pilot training, however the simulation accuracy fulfils Level-D standard for most parameters that are relevant for flight mechanic investigations (such as the aircraft motion) $[24,25]$.

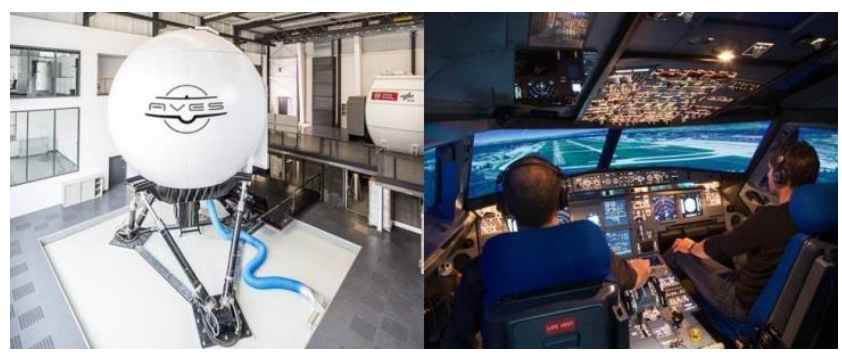

Fig. 12 The motion-based AVES A320 research simulator

For further demonstration and test of the assistance system in manual flight a test campaign was conducted in the AVES A320 simulator with three pilots. All of these are airline pilots with experience on different aircraft types. However, all pilots were familiar with Airbus fly-by-wire aircraft.

The task for the pilots was to perform an ILS-approach and a manual landing on runway $25 \mathrm{C}$ at EDDF Frankfurt/Main airport (Germany) under different crosswind conditions ranging from $0 \mathrm{kts}$ to $40 \mathrm{kts}$ crosswind at touchdown. Along the glidepath the wind was varied in terms of speed and direction ending up in a pre-defined wind direction and speed at $10 \mathrm{~m}$ above the runway in order to give a realistic feeling of the wind variation during the approach to the pilots. For the completeness also the clouds and visibility were adapted in a way to give a look of a realistic weather scenario with strong winds. The following METAR, inspired by a real METAR from EDDF on 13th January 2017, was given to the pilots during the briefing representing the exemplary weather conditions:

\section{EDDF 121230Z 17019G29KT 999 -RA FEW006 BKN010 BKN030 5/4 Q988,}

meaning a wind direction of $170^{\circ}$ with $19 \mathrm{kts}$ average wind speed and gusts up to 29 kts (during the simulations the wind direction at $10 \mathrm{~m}$ above the runway was fixed to $170^{\circ}$, whereas the wind speed was varied), good visibility (set to $10 \mathrm{~km}$ in the simulation), light rain, few clouds in $600 \mathrm{ft}$ agl., a broken cloud layer in $1000 \mathrm{ft}$ agl. and another broken cloud layer in $3000 \mathrm{ft}$ agl., a temperature of $5^{\circ} \mathrm{C}$, dewpoint of $4^{\circ} \mathrm{C}$ and a QNH of $988 \mathrm{hPa}$. Gusts were not implemented in the simulation. Generally, all approaches and landings were simulated without atmospheric turbulence in order to allow the full comparability of the test runs. This should prevent that a possible degradation of the pilots' performance is only due to the crosswind and not due to the turbulence, which typically increases with increasing wind speed. However, in order to also consider the effect of increasing turbulence with increasing wind speed and to give a more realistic feeling to the pilot, some approaches were also simulated with atmospheric turbulence using the turbulence spectrum of Dryden [26,27]. Figure 13 gives two exemplary sketches of the outside view during the approach, showing the cloudy weather. On the right hand photo the airport and the runway is already in sight in the background.

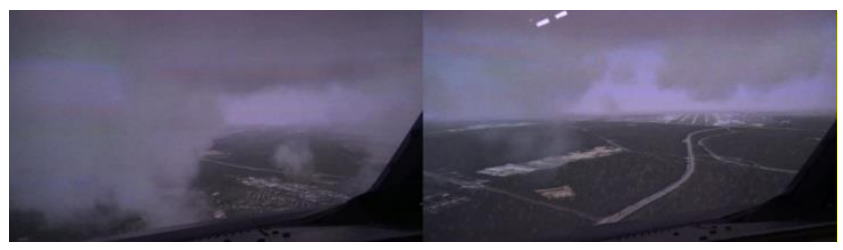

Fig. 13 Exemplary outside views during final approach

Given the small number of pilots, hence the relatively small number of crosswind landings the results can only indicate general trends and cannot serve for a quantitative assessment. Nevertheless, the simulations demonstrate well how effectively the assistance system performs.

Figure 14 shows the ground track of each landing. The figure does not distinguish between different crosswinds but just depicts the lateral deviation from the runway centerline with and without the assistance system. The boundaries of the plot are set to a lateral deviation from the centerline of $+/-30 \mathrm{~m}$ as the runway width is $60 \mathrm{~m}$. Hence, ground tracks that exceed the plot show an (at least temporary) runway excursion. It must be noted that some problems of the pilots with directional control under very strong crosswind can most likely be attributed to the hardware of the simulator, its visual and motion cues provided to the pilot and the haptics and characteristics of the control devices. Especially the pedal forces are known not to be comparable to real flight conditions. This can be one reason for problems of the pilots with lateral control on ground. Most likely the runway excursions that occurred during the simulations would not occur under real flight conditions. Nevertheless, the mentioned deficiencies of the simulator are always present so that a relative comparison between different landings under different crosswind conditions is assumed to be valid. 


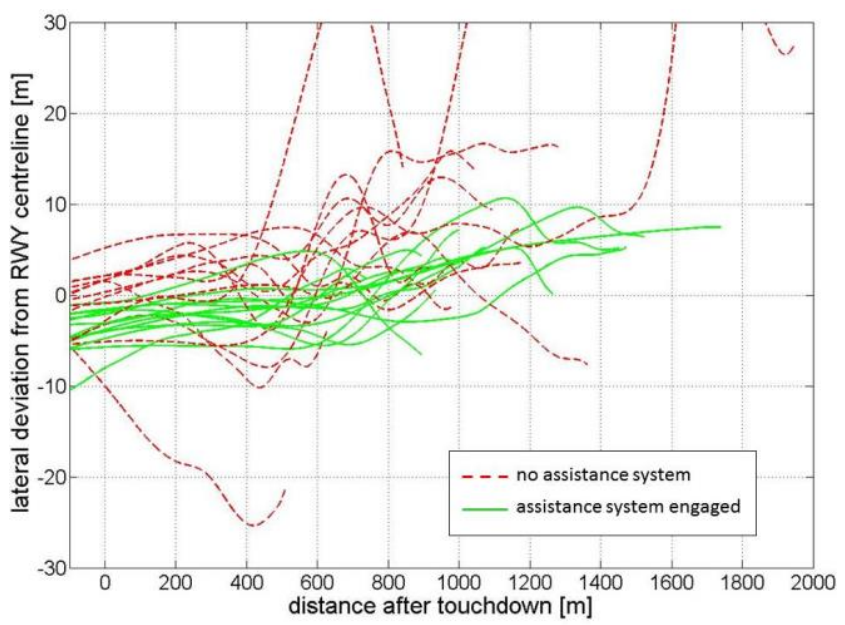

Fig. 14 Ground tracks after touchdown with and without assistance system (all crosswinds from $0 \mathrm{kts}$ to $40 \mathrm{kts}$ )

Figure 14 clearly outlines that the lateral deviations on the runway are much smaller with the assistance system engaged. Also, the tracks with the system engaged are much smoother and less curved, which indicates a lesser control action than without the assistance system. The fact that many tracks with the assistance system engaged end slightly offside the centerline is due to some pedal inputs by the pilots. Although the assistance system would not require any control input by the pilot on the runway, most pilots tended to give at least some manual control inputs. This is mostly attributed to the different kind of ground control in case the assistance system is engaged. However, even as the way to manually control the aircraft on the runway with the assistance system engaged was new to the pilots, they got used to it quickly. No pilot had general objections on this kind of lateral control on ground.

Figure 15 depicts the maximum lateral deviation from the runway centerline that occurred during each landing run as a function of the crosswind component. As can be expected the lateral deviations generally increase with increasing crosswind. Without crosswind no simulations were performed with the assistance system engaged as in this case no crab angle occurs. These simulations can serve as a reference. One can observe that even without crosswind lateral deviations on the runway of a few meters but less than $10 \mathrm{~m}$ occur. These deviations could partly be attributed to simulator deficiencies and shall be considered as the nominal case of a safe landing. Figure 15 shows that for all crosswind conditions the lateral deviations with the assistance system engaged are in the same range as the nominal case without crosswind. Without the assistance system the lateral deviations increase with increasing crosswind and are always larger than with the assistance system engaged.

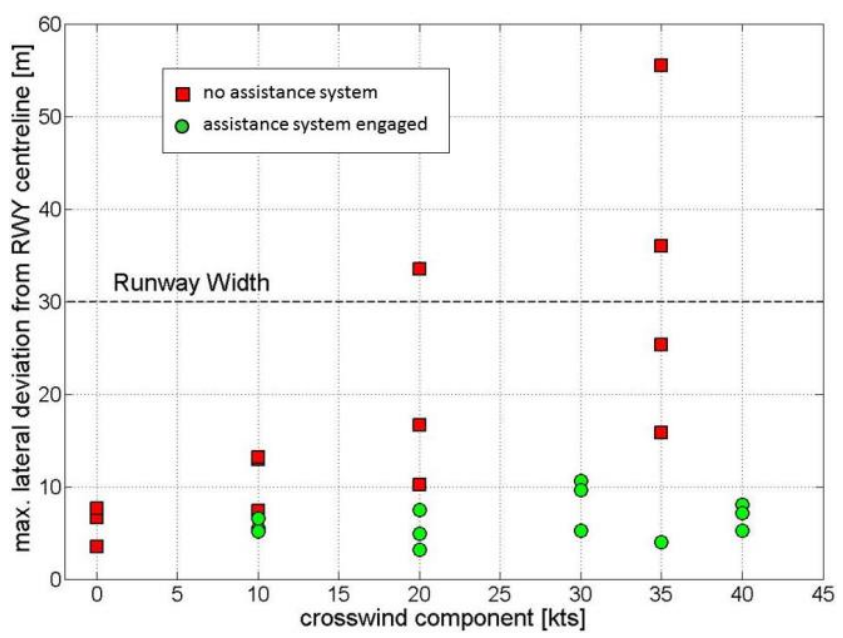

Fig. 15 Maximum lateral deviation from runway centerline as a function of the crosswind component with and without assistance system

Touching down as well as decelerating in crabbed motion inevitably results in lateral accelerations. However, even if a decrab maneuver is performed, hence the aircraft touches down and decelerates in runway direction, lateral accelerations occur as well due to the steering on the runway.

Figure 16 outlines the maximum lateral load factor $n_{y}$ that occurred during the landing.

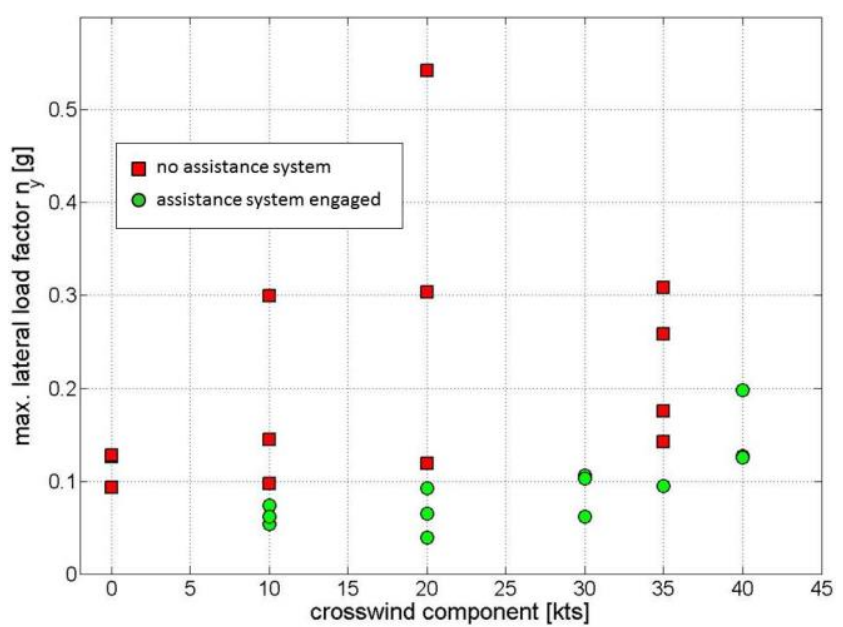

Fig. 16 Maximum lateral load factor as a function of the crosswind component with and without assistance system 
One can observe in the figure that with the assistance system engaged the maximum lateral load factor increases with increasing crosswind. This increase is caused by the increasing crab angle that leads to larger side forces during deceleration on the runway. Nevertheless, the lateral load factors are always significantly smaller with the assistance system engaged than without it. Without the assistance system the lateral steering activities result in significantly larger side forces or load factors, respectively. These results imply that for passenger comfort considerations the crabbed motion during operations with the assistance system engaged is not crucial.

However, the reduction of lateral forces could possibly be beneficial for the design of the landing gear. Figure 17 depicts the maximum side force of the main gears. It should be noted that here the main gear side force is in the aircraft's body-fixed co-ordinates. This means that due to the steering of the main landing gear this force is a sideforce for the landing gear strut, not for the wheel and tire.

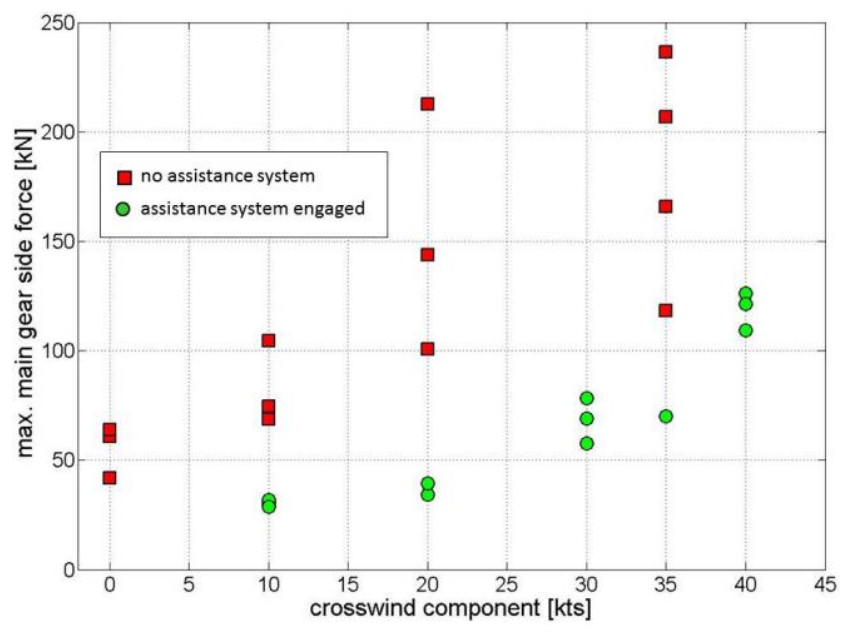

Fig. 17 Maximum main gear side force as a function of the crosswind component with and without assistance system

Figure 17 shows how remarkably smaller the maximum gear forces are when the assistance system is engaged and the main gear is steered in runway direction. This significant reduction of side forces could possibly be used for a lighter design of the landing gear struts. If this was possible at least some of the weight for the actuation of the main gear steering could be compensated. However, the impact of the reduced loads on the landing gear design still needs to be thoroughly assessed.

\section{Conclusions and open research topics}

A crosswind assistance system that makes use of steerable main landing gears was designed and successfully tested in offline simulations and pilot-in-the-loop trials in a motion-based flight simulator. The investigations presented here show a great potential of a crosswind assistance system using steerable main landing gears especially for future unconventional aircraft configurations. The demands on the pilot during crosswind landings can be reduced significantly, since an aircraft equipped with such a system can be landed in crabbed motion without the necessity to perform a de-crab maneuver. This is expected to be especially beneficial for many future aircraft configurations suffering from controllability deficiencies under crosswind operations, such as blended wing bodies or aircraft with very high aspect-ratio wings.

The study was performed in DLR's Air Vehicle Simulator AVES using an A320 simulation model. Although the AVES full-flight simulator is not intended for pilot training the simulation accuracy is considered acceptable for the scientific purpose of this study.

The performance of the assistance system was satisfactory under the tested crosswind conditions ranging up to crosswind components of $40 \mathrm{kts}$. The maximum deviations from the runway centerline were always below a few meters. Also, the special control philosophy for steering the aircraft manually on ground was quickly accepted by the pilots. Of course operations of an aircraft equipped with such assistance system and steerable main landing gears must be subject to pilot training in order to familiarize pilots with the special requirements of crabbed landings.

What could also be shown in the simulations is a significant reduction $(>50 \%)$ of the side-forces acting on the landing gears during touch-down and roll-out using the crosswind assistance system. However, there is still a need for further investigation in various areas.

Whether the reduction of side-forces acting on the landing gear can be translated into a lighter landing gear could not be shown yet. Still, the hope is that at least part of the additional weight of the main gear steering actuators could be saved by a lighter landing gear assembly. Many design issues such as a detailed failure case assessment (e.g. to prevent locking of the landing gear in a wrong steering direction) or prevention of undesired shimmy are still to be investigated. As the steering functionality of the main landing gear is safety critical it will probably also strongly affect the certification of the landing gear. For answering all those question further investigation in landing gear design is necessary and cooperation with landing gear specialists (e.g. manufacturers) would be desirable. 
Another area of research interest is on the use of the crosswind assistance system for take-off. It would be useful to design a take-off crab controller similar to the crab controller for landing described here and to investigate on operational benefits. Take-off has not been considered yet in the recent work, but first conceptual ideas exist on the functionality of take-off crosswind assistance. In order to allow an efficient and break-free transition from taxi to take-off the take-off run should be started with the landing gears aligned in aircraft direction. With increasing speed the crosswind assistance system should slowly head the aircraft into the wind, while constantly keeping the aircraft on the runway centerline. At rotation speed the crab angle should fully counteract the crosswind so that the sideslip angle is zero at lift-off. Preferably, a study on take-off crosswind assistance would incorporate flight simulator tests for pilot-in-the-loop investigations such as the one presented in section 4 .

The work on crosswind assistance using steerable main landing gears presented here was performed on the basis of a state-of-the-art aircraft configuration, namely the A320, which does not suffer extraordinary challenges for crosswind operations. It is expected that this circumstance does not change the general conclusion on the potential benefit of the assistance system for aircraft configurations that show challenging crosswind-related characteristics. Nevertheless, it would be of great interest to actually test one of those aircraft configurations, such as blended wing body or aircraft with very high aspect ratio wings, with the steerable main landing gear and the crosswind assistance system. In various research projects simulation models of such kinds of aircraft have been developed, hence it would be relatively easy to adapt an existing landing gear model of such simulation models in terms of main gear steering and to adapt and implement the assistance system. This way, operational aspects of such unconventional aircraft configurations could be further investigated.

\section{References}

[1] E. Torenbeek, Advanced Aircraft Design, A. John Wiley \& Sons, Ltd, Chichester, UK, 2013.

[2] J. J. Lee et al., Historical and Future Trends in Aircraft Performance, Cost, And Emissions, Annual Review of Energy and the Environment, Vol. 26, 2001, pp.167-200.

[3] A. Bows, Aviation and climate change: confronting the challenge, The Aeronautical Journal, Vol. 114, No. 1158, August 2010, pp.459-468.
[4] M. K. Bradley and C. K. Droney, Subsonic Ultra Green Aircraft Research: Phase I Final Report, NASA/CR-2011-216847, April 2011.

[5] Y. J. Hasan et al., Handling Qualities Assessment of a Blended Wing Body Configuration under Uncertainty Considerations, German Aerospace Congress, Munich, Germany, 5 - 7 September 2017.

[6] R. H. Liebeck, Design of the Blended Wing Body Subsonic Transport, Journal of Aircraft, Vol. 41, No. 1, January - February 2004.

[7] F. Kauth et al., Progress in Efficient Active High-Lift, AIAA-2017-3559, 35th AIAA Applied Aerodynamics Conference, 5 - 9 June 2017.

[8] J. P. Campbell, Status of V/STOL Research and Development in the United States, Journal of Aircraft, Vol. 1, No. 3, May - June 1964.

[9] H. C. Quigley and R. C. Innis, Handling Qualities and Operational Problems of a Large Four-Propeller STOL Transport Airplane, NASA TN D-1647, January 1963.

[10] J. H. Diekmann, Flight Mechanical Challenges of STOL Aircraft Using Active High-Lift, AIAA-20173561, 35th AIAA Applied Aerodynamics Conference, 5 - 9 June 2017.

[11] Flight Safety Digest, Approach and Landing Accident Reduction, Briefing Note 8.7, Crosswind Landings, Flight Safety Foundation, 2000.

[12] N.N., A320 FCOM Bulletin, No 21, Crosswind Landing Techniques, September 1992.

[13] D. Vechtel, U. M. Meissner and K.-U. Hahn, On the use of a steerable main landing gear for crosswind landing assistance, CEAS Aeronautical Journal, Vol. 5, 2014, pp. 293-303, doi 10.1007/s13272-014-01072.

[14] O. W. Loudenslager, Cross-Wind Airplane Landing Gear, US Patent US2504077, 11 April 1950.

[15] N.N., Aircraft Specification No. A-790, Cessna 190/195, Federal Aviation Administration FAA, Department of Transportation, Revision 36, 31 March 2003.

[16] The Boeing Company, B-52H Flight manual, T-O. 1B-52H-1, Change 22, 1 June 2006.

[17] B. K. Rawdon and C. H. Zachary, Method, System, and Computer Program Product for Controlling Maneuverable Wheels on a Vehicle, US Patent US6,722,610B1, 20 April 2004.

[18] K.-U. Hahn and U. M. Meissner, Control Device for Aircraft, US Patent US 2012/0305704 A1, 6 December 2012 .

[19] N.N., A320 Flight Crew Operating Manual Part 3 Flight Operations, 01 June 2009. 
[20] C. Raab, Flugdynamisches Simulationsmodell A320ATRA - Validierungsversuche und Bewertung der Modellgüte (English: Flight Dynamics Simulation Model A320 ATRA - Validation Tests and Evaluation of the Model Accuracy), DLR internal report, IB 111-2012/43, 2012..

[21] D. Fischenberg, A Validated Dynamic Simulation Model for VFW-614 Ground Handling, DLR internal report, IB 111-98/33, 1998.

[22] A. G. Barnes and T. Y. Jager, Enhancement of Aircraft Ground Handling Simulation Capability, AGARDograph No. 333, 1998.

[23] N.N., A320 Flight Crew Operating Manual Part 1 Systems Description, 01 December 2008.

[24] H. Duda and T. Gerlach, Design of the DLR AVES Research Flight Simulator, AIAA-2013-4737, AIAA Modeling and Simulation Technologies Conference, Boston, USA, $19-22$ August 2013, doi:10.2514/6.2013-4737.

[25] N.N., Joint Aviation Requirements, JAR-STD 1A Aeroplane Flight Simulators. JAA Joint Aviation Authorities, 1999.

[26] N. N., U.S. Military Handbook MIL-HDBK-1797, 19 December 1997.

[27] Dryden, H. L., A review of the statistical theory of turbulence, Quarterly of Applied Mathematics, Vol. 1, No. 1, April 1943, pp. 7-42.

[28] van Es, G. W. H., van der Geest, P. J. and Nieuwpoort, T. M. H., Safety aspects of aircraft operations in crosswind, Nationaal Lucht- en Ruimtevaartlaboratorium, NLR-TP-2001-217, May 2001.

[29] N.N., PEP Performance Programs Manual, Airbus Industries. 